\title{
Synthesis and Properties of Hydrophilic Polymers \\ I. Preparation and Metal Complexation of Poly(4-vinylpyridine-co- $N$-allylthiourea)
}

\author{
Kurt E. GECKELER \\ Institute of Organic Chemistry, University of Tübingen, \\ Auf der Morgenstelle 18, W-7400 Tübingen, Germany
}

(Received February 24, 1992)

\begin{abstract}
Copolymers of 4-vinylpyridine and $\mathrm{N}$-allylthiourea with different mole fractions were synthesized by radical copolymerization in bulk. The AIBN-initiated copolymerization was found to strongly favor the 4-vinylpyridine monomer in the copolymer composition. This was confirmed by viscosity measurements with a linear relationship between the reduced viscosity and the comonomer content. Interactions and complexation of the water-soluble copolymers with nine metal ions were investigated in aqueous solution by means of a membrane filtration technique. This technique is designed to remove and separate metal ions from diluted solutions by binding them to soluble polymers. The effects of several parameters, such as copolymer composition, filtration factor, and $\mathrm{pH}$ were studied as a function of the interaction of the copolymers with metal ions. A strong selectivity for copper(II) was found which was pronounced at a monomer ratio of $1: 2$ (4-vinylpyridine: $N$-allylthiourea). Also a partial interaction of iron(III) and the copolymer (2:1) was observed at $\mathrm{pH} 3$ which was strongly $\mathrm{pH}$-dependent.

KEY WORDS N-Allylthiourea / Aqueous Solution / Copolymerization / Metal Complexation / 4-Vinylpyridine /
\end{abstract}

Hydrophilic polymers represent an important class of polymeric materials due to their salient properties and their great spectrum of practical applications. A number of different polymer structures can provide the desired properties of materials with respect to the application purpose. $^{1,2}$ A hydrophilic character of the polymer and compatibility with many polar solvents are especially suitable that can be attained by introducing solubilizing constitutional repeat units by copolymerization. Among these, pyridine groups play an essential role by reason of the chemical functionality of such materials as well as the commercial availability of the corresponding monomers.

Fundamental studies on the homopolymerization and copolymerization of the 4vinylpyridine monomer have been the subject of a number of studies. ${ }^{3}$ The metal binding affinity of pyridines as monomeric and polymeric derivatives is well-known. ${ }^{4}$ Poly(4vinylpyridine)s have been also investigated in terms of their metal complexing behavior. ${ }^{5,6}$ Nishide and Tsuchida investigated the selective adsorption of metal ions on resins based on 4-vinylpyridine. ${ }^{7}$ In that study, fixed coordination sites were produced using a template technique with 1,4-bromobutane as crosslinking agent. Additionally, another study showed that the incorporation of pyridine moieties has an enhancing effect on the stability of metal complexes. ${ }^{8}$ However, very few studies focus on the properties of poly(4-vinylpyridine)s and copolymers in aqueous solution. ${ }^{2,9}$

Previously, $N$-allylthiourea copolymers with acrylic acid were reported and studied as macromolecular complexing agents. ${ }^{10}$ In more detail, the influence of the thiourea ligand on 
the complexation behavior was investigated for several basis polymers. ${ }^{11}$

This article describes the preparation of novel copolymers based on 4-vinylpyridine and $\mathrm{N}$-allylthiourea by radical bulk copolymerization and the investigation of their complexation behavior towards metal ions in aqueous phase in terms of removability and enrichment from dilute solutions.

\section{EXPERIMENTAL}

\section{Materials}

4-Vinylpyridine (1) was purchased from Aldrich and freshly distilled prior to use. $N$-Allylthiourea (2) and 2,2'-azoisobutyronitrile (AIBN) were obtained from Merck and dried in vacuo at room temperature. All salts were of analytical-reagent grade and used as received. The other reagents and solvents were purified by ordinary methods.

\section{Copolymerization Procedure}

The copolymers (systematic name: poly[1(4-pyridinyl) ethylene-co-1-(thioureido methyl) ethylene]) were synthesized free radically in bulk under nitrogen using AIBN as the initiator. A mixture of $\mathbf{1}$ and $\mathbf{2}$ in the defined molar ratios and AIBN $(0.5 \mathrm{~mol} \%)$ were placed into ampules with magnetic stirrers, degassed by several freeze-thaw cycles, sealed under vacuum, and heated in a glycol bath of $70^{\circ} \mathrm{C}$ under stirring. After the ampules were cooled and opened, the copolymers were dissolved in deionized water and purified by ultrafiltration using a conventional membrane filtration system. ${ }^{12}$ The retentate solutions were concentrated in vacuo and then freeze-dried. The experimental data are summarized in Table I.

Results of the fractionation experiments performed with copolymer $\mathbf{3 c}$ using a membrane filtration technique in aqueous solution are presented in Figure 1.

\section{Measurements}

Elemental analyses were conducted in the
Table I. Experimental data of the copolymerization of 4-vinylpyridine (1) with $N$-allylthiourea (2) in bulk using $2,2^{\prime}$-azoisobutyronitrile as initiator at $70^{\circ} \mathrm{C}$

\begin{tabular}{|c|c|c|c|c|}
\hline \multirow[t]{2}{*}{ No. } & $\begin{array}{l}\text { Feed } \\
{[\mathbf{1}]_{0}}\end{array}$ & $\begin{array}{c}\text { Product }^{\mathrm{a}} \\
\text { [1] }\end{array}$ & $\operatorname{Time}^{\mathrm{b}}$ & Conversion $^{\mathrm{c}}$ \\
\hline & $\overline{[1]_{0}+[\mathbf{2}]_{0}}$ & $\overline{[1]+[2]}$ & $\min$ & $\%$ \\
\hline $3 a$ & 0.10 & - & $>72 \mathrm{~h}^{\mathrm{d}}$ & 14 \\
\hline 3b & 0.33 & 0.81 & 60 & 31 \\
\hline $3 c$ & 0.50 & 0.86 & 45 & 68 \\
\hline $3 d$ & 0.66 & 0.95 & 45 & 68 \\
\hline $3 e$ & 0.90 & 95 & 45 & 88 \\
\hline
\end{tabular}

a Determined via elemental analysis and UV spectroscopy.

b Period until solidification.

c Values are referred to a copolymer fraction of $M>10000 \mathrm{~g} \mathrm{~mol}^{-1}$ (retentate fraction) determined after ultrafiltration through a membrane with a molar mass exclusion limit of $10000 \mathrm{~g} \mathrm{~mol}^{-1}$.

${ }^{\mathrm{d}}$ No solidification observed.

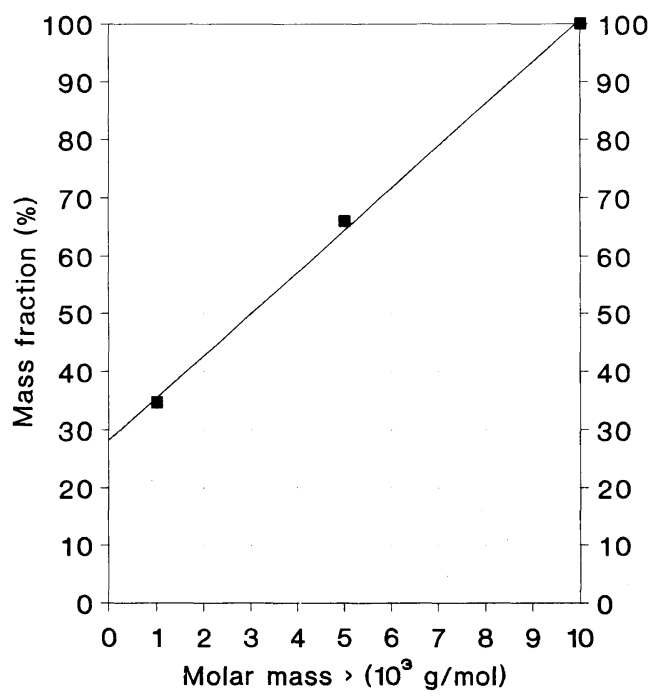

Figure 1. Fractionation of copolymer $3 \mathbf{c}$ by membrane filtration (polysulfone membranes with nominal molecular mass exclusion limits of 1000,5000 , and $10000 \mathrm{~g} \mathrm{~mol}^{-1}$ ) in aqueous solution.

microanalytical laboratory at our institute. $\mathrm{pH}$ measurements were carried out with an E 512 $\mathrm{pH}$ meter (Metrohm). Metal ion concentrations were determined using a Perkin Elmer Atomic Absorption Spectrometer 1100. A 
rotation vicosimeter VT 8 (Haake) and a capillary viscosimeter (Schott) served for viscosity measurements.

\section{Metal Ion Complexation Studies}

The complexation studies were performed with a membrane filtration system consisting of an ultrafiltration cell, a polysulfone membrane or equivalent (molecular mass exclusion limit: $10000 \mathrm{~g} \mathrm{~mol}^{-1}$ ), a reservoir, a selector, and a regulator. Nitrogen served as a pressure source and the pressure was kept constant at $300 \mathrm{kPa}$ during the studies.

To study the interaction behavior of the metal ions, an aqueous solution of the cations ( $20 \mathrm{mg}^{-1}$ of each metal ion) was placed into the cell containing the copolymer solution $(2 \mathrm{wt} \%)$. The system was pressurized and the cell washed with the reservoir solution. Metal ion concentrations in the retentate and in the permeate were determined by atomic absorption spectrometry. Fundamentals and details of the procedure have been already described. ${ }^{11,12}$

\section{RESULTS AND DISCUSSION}

The free radical copolymerization of 4vinylpyridine with $N$-allylthiourea in bulk has been studied with two different mole fractions in the feed.

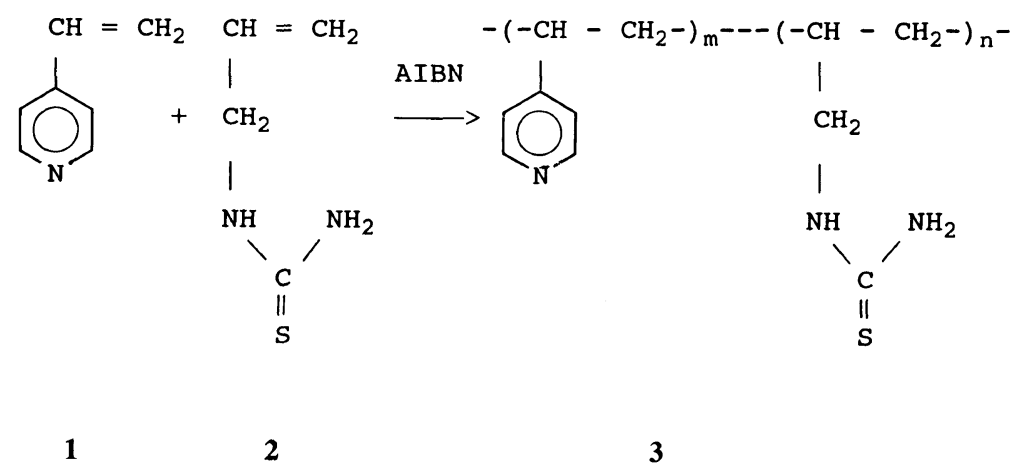

Feed and copolymer composition and other experimental data are summarized in Table I. According to the experimental results, monomer $\mathbf{1}$ is strongly favored in the copolymer composition as expected due to its high polymerization affinity compared to monomer 2.

That is also shown in the plot of the reduced viscosity versus the content of $\mathbf{2}$ (Figure 2 ). The contents of $\mathbf{2}$ attained were lower than about $20 \%$, showing a linear and strong decrease of the reduced viscosity with increasing content of 2. This indicates the reduction of the molecular mass with higher contents of $\mathbf{2}$ in the copolymers.

Allyl monomers are known to give low conversions and low-molecular mass products. This effect is confirmed in the series of the copolymers $\mathbf{3 a}-\mathbf{3 e}$, in which with increasing mole fraction of $\mathbf{2}$ the conversion was lowered from $88 \%$ to $14 \%$ (Table I). The results are in agreement with the general tendency of lowering the polymerization degree of allylic monomers by autoinhibition.

As homopolymerization of $\mathrm{N}$-allylthiourea leads to water-soluble products, copolymerization with this hydrophilic comonomer can provide hydrosolubility. The copolymers $\mathbf{3 a}-$ 3e were soluble in water up to $\mathrm{pH}$. The $\mathrm{pH}$ limitation of solubility is due to the influence of the pyridine moieties in the copolymer.

Although there is a broad application po- 
tential of such copolymers, we focus in this study on the metal ion interaction properties in homogeneous aqueous phase. To this end, the complexation behavior has been studied using a membrane-based technique. ${ }^{11,12}$ Thereby, the retention $R$, which is defined as the ratio of the concentration in the retentate $\left(c_{\mathrm{r}}\right)$ and the initial concentration $\left(c_{0}\right)$ of metal ions, by a polymeric ligand is investigated. Separation of the low-molecular ions from the

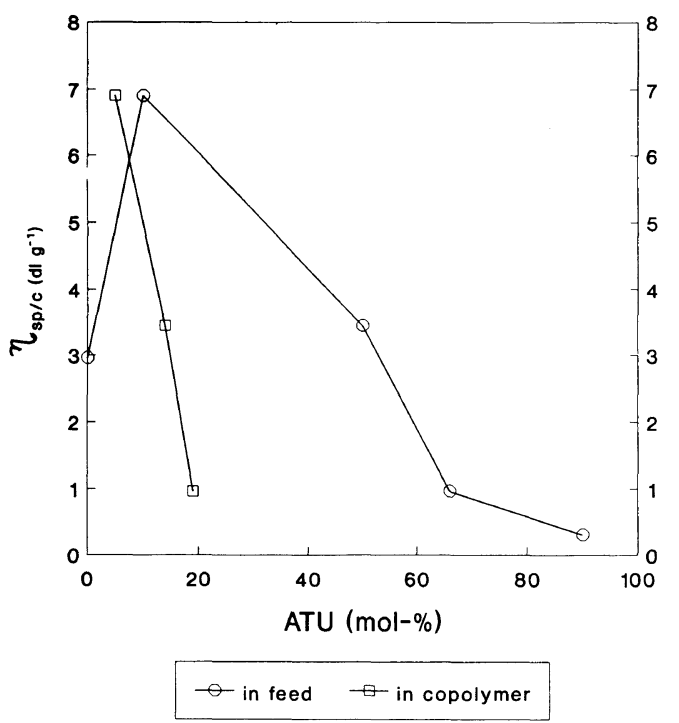

Figure 2. Reduced viscosity of the copolymers of 4-vinylpyridine (1) and $N$-allylthiourea (2) as a function of the content of 2 at $25^{\circ} \mathrm{C}\left(c=0.5 \mathrm{~g} \mathrm{dl}^{-1}\right)$. macromolecules is performed by membrane filtration. The polymeric metal complexes were found to be completely water-soluble. No precipitation occurred for copolymer complexes with the metals investigated.

Figure 3 illustrates the relationship between the retention of nine metal ions and the filtration factor $Z$ which is the quotient of the volume of permeate $V_{\mathrm{p}}$ and the volume of retentate $V_{0}$.

The results of the interaction studies of copolymer 3d evidently show that at $\mathrm{pH} 1$ no retention of metal ions could be observed except for copper and cadmium with relatively low values of about 15 and $20 \%$. At pH 3, however, iron and copper exhibited values of about $60 \%$ retention, chromium and cadmium of about $20 \%$ under these equilibrium conditions. This is in agreement with the known preference of the $\mathrm{N}$-allylthiourea group towards certain metals. ${ }^{10,11}$ The representative of the alkali metals, potassium, showed no interaction at all, as expected.

The situation is different when changing the copolymer composition to a monomer feed ratio of $1: 2$ (3b) (Table II).

$\mathrm{Cu}(\mathrm{II})$ exhibited a remarkable binding affinity toward 3. Thus, a distinct selectivity for copper(II) is attained with retention values of about $100 \%$. Only chromium $(40 \%)$ and iron $(15 \%)$ interacted slightly with the

Table II. Retention values of poly(4-vinylpyridine-co- $N$-allylthiourea) (3b) for a series of metal ions in aqueous solution ( $\mathrm{pH} 3)$

(Filtration factor $Z=V_{\mathrm{p}} V_{0}^{-1}$ )

\begin{tabular}{rccccccccc}
\hline$Z$ & $\mathrm{~K}^{+}$ & $\mathrm{Cr}^{3+}$ & $\mathrm{Fe}^{3+}$ & $\mathrm{Co}^{2+}$ & $\mathrm{Ni}^{2+}$ & $\mathrm{Cu}^{2+}$ & $\mathrm{Zn}^{2+}$ & $\mathrm{Cd}^{2+}$ & $\mathrm{Pb}^{2+}$ \\
\hline 1 & 64.0 & 91.0 & 84.5 & 78.0 & 76.5 & 100.0 & 76.5 & 80.5 & 93.0 \\
2 & 30.0 & 82.0 & 67.5 & 55.0 & 51.5 & 100.0 & 52.5 & 59.0 & 66.0 \\
3 & 3.0 & 75.5 & 53.5 & 36.0 & 31.5 & 100.0 & 33.5 & 42.5 & 44.0 \\
4 & 0 & 69.5 & 42.5 & 21.5 & 15.5 & 100.0 & 19.5 & 30.5 & 27.5 \\
5 & 0 & 64.0 & 34.0 & 10.0 & 3.5 & 100.0 & 9.5 & 21.5 & 16.5 \\
6 & 0 & 60.5 & 29.5 & 4.0 & 0 & 100.0 & 4.5 & 16.0 & 10.5 \\
7 & 0 & 56.5 & 24.5 & 0 & 0 & $100 / 0$ & 0 & 10.5 & 5.0 \\
8 & 0 & 50.5 & 20.5 & 0 & 0 & 98.5 & 0 & 7.0 & 3.5 \\
9 & 0 & 45.0 & 17.5 & 0 & 0 & 98.0 & 0 & 4.0 & 2.0 \\
10 & 0 & 40.5 & 15.0 & 0 & 0 & 97.5 & 0 & 1.5 & 1.5
\end{tabular}


Synthesis and Properties of Hydrophilic Polymers I.

$\mathrm{Cr}$

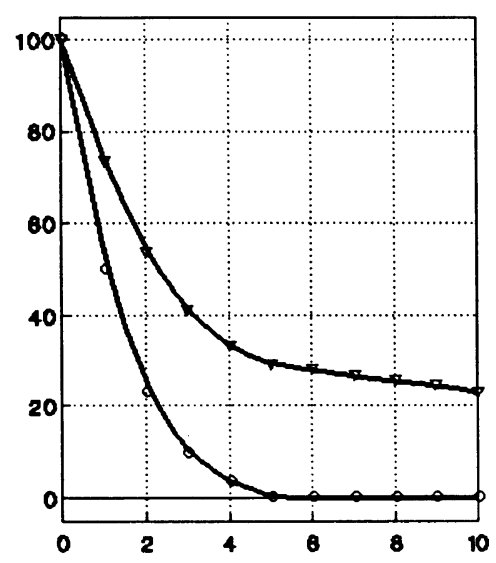

Co

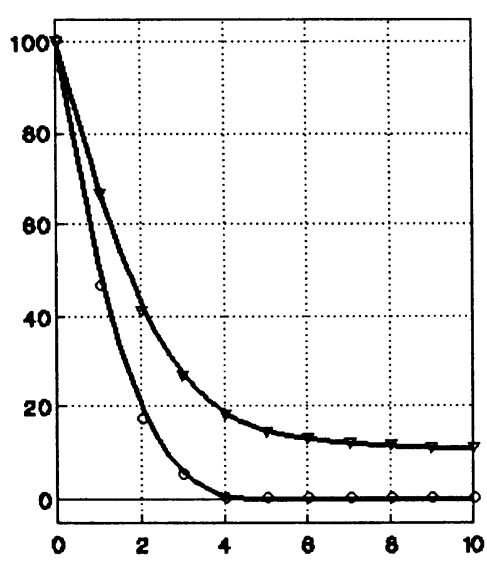

$\mathrm{Cu}$

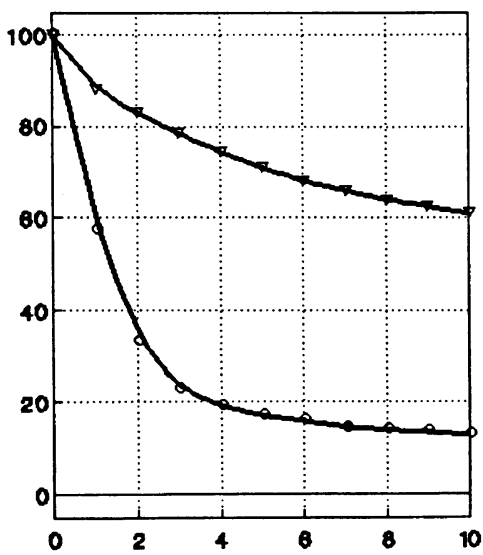

$\mathrm{Fe}$

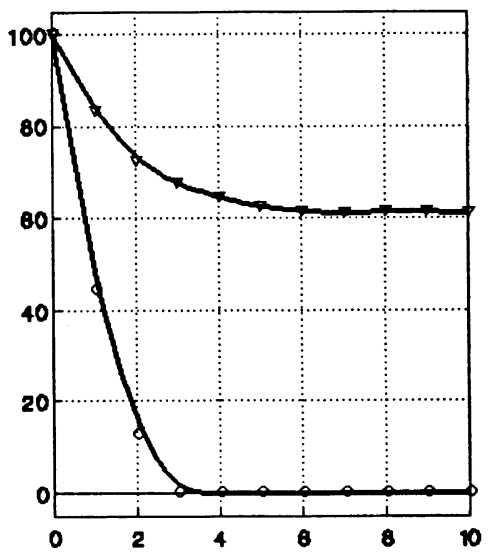

$\mathrm{Ni}$

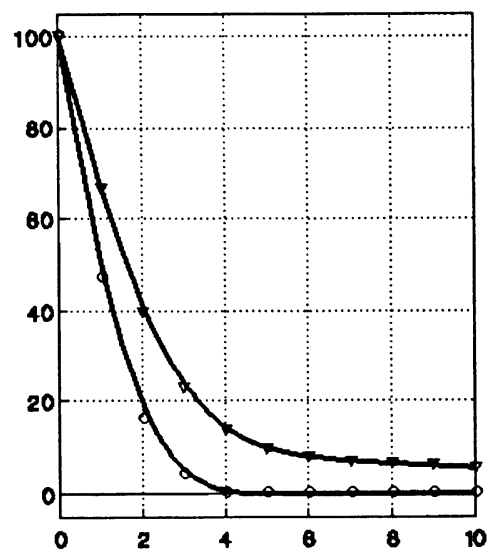

Zn

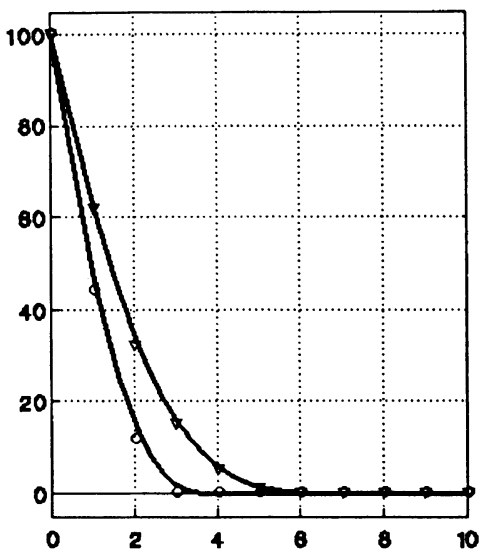

Figure 3. 
Cd

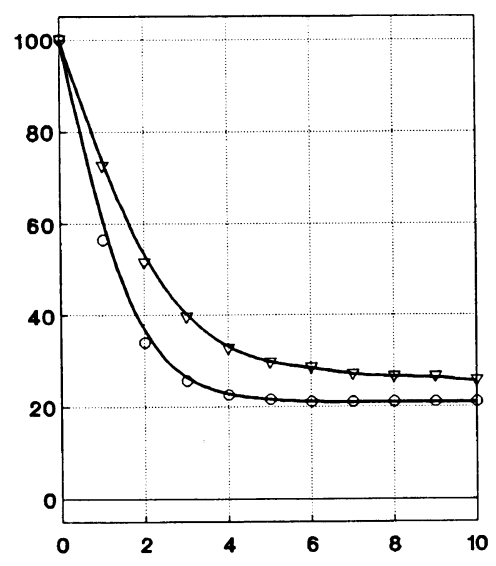

$\mathrm{K}$

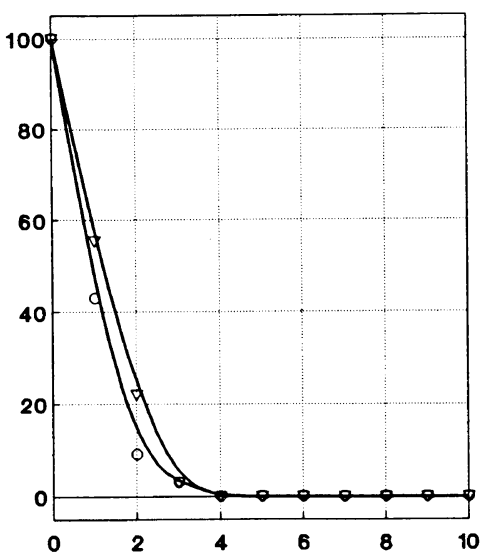

$\mathrm{Pb}$
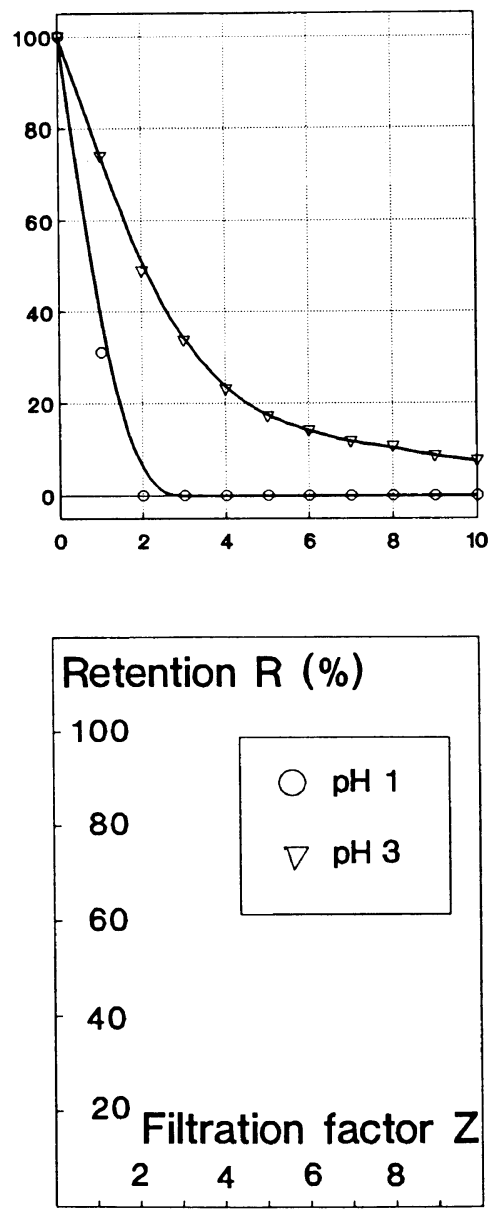

Figure 3. Rentention $R\left(=c_{\mathrm{r}} c_{0}^{-1}\right)$ of a series of metal ions for poly(4-vinylpyridine-co- $N$-allylthiourea) (3d) as a function of the filtration factor $Z\left(=V_{\mathrm{p}} V_{0}^{-1}\right)$ at different $\mathrm{pH}$.

copolymer whereas all other cations were not retained (retention about zero). If a solution contains chromium and copper, both ions can be removed at $Z=4$ up to $70 \%$ and $100 \%$, respectively, from dilute solutions.

By calculating the separation factors of copolymer $\mathbf{3 b}$ for copper, the salient selectivity for this metal versus iron, cobalt, nickel, zinc, cadmium, and lead is confirmed (Table III). Correspondingly, the very low selectivity of copolymer $\mathbf{3 d}$ is also corroborated.

Relative retention values of $\mathbf{3 b}$ and $\mathbf{3 d}$ for several metal ions are plotted in Figure 4.

It is clearly shown that copolymer $\mathbf{3 d}$ retained better $\mathrm{Fe}(\mathrm{III}), \mathrm{Cd}(\mathrm{II})$, and $\mathrm{Co}(\mathrm{II})$ ions compared to $\mathbf{3 b}$. On the contrary, polymer $\mathbf{3 b}$ with a higher content of repeat units of monomer 2, exhibits a better retention for $\mathrm{Cr}(\mathrm{III})$ and especially for $\mathrm{Cu}(\mathrm{II})$ which is indicated by negative $\Delta R$ values in the diagram. From these results it can be concluded that the stereochemical arrangement of binding sites of the copolymer is essentially influenced by the copolymer composition, i.e., its primary 
Table III. Separation factors $\beta$ for copper(II) and a number of metal ions ( $\mathrm{M}^{n+}$ ) for the copolymers $\mathbf{3 b}$ and $\mathbf{3 d}$ at two different filtration factors $Z(\mathrm{pH} 3)$

\begin{tabular}{|c|c|c|c|c|c|c|c|c|c|}
\hline \multirow{2}{*}{ No. } & \multirow{2}{*}{$Z$} & \multicolumn{8}{|c|}{$\mathrm{M}^{n+}$} \\
\hline & & $\mathrm{K}^{+}$ & $\mathrm{Cr}^{3+}$ & $\mathrm{Fe}^{3+}$ & $\mathrm{Co}^{2+}$ & $\mathrm{Ni}^{2+}$ & $\mathrm{Zn}^{2+}$ & $\mathrm{Cd}^{2+}$ & $\mathrm{Pb}^{2+}$ \\
\hline \multirow[t]{2}{*}{$\mathbf{3 b}$} & 5 & 100.0 & 1.6 & 2.9 & 10.0 & 28.6 & 10.5 & 4.6 & 6.1 \\
\hline & 10 & 97.5 & 2.4 & 6.5 & 97.5 & 97.5 & 97.5 & 65.0 & 65.0 \\
\hline \multirow[t]{2}{*}{ 3d } & 5 & 71.0 & 2.5 & 1.1 & 4.9 & 7.5 & 71.0 & 2.4 & 4.2 \\
\hline & 10 & 61.0 & 2.7 & 1.0 & 5.6 & 11.1 & 61.0 & 2.4 & 8.1 \\
\hline
\end{tabular}

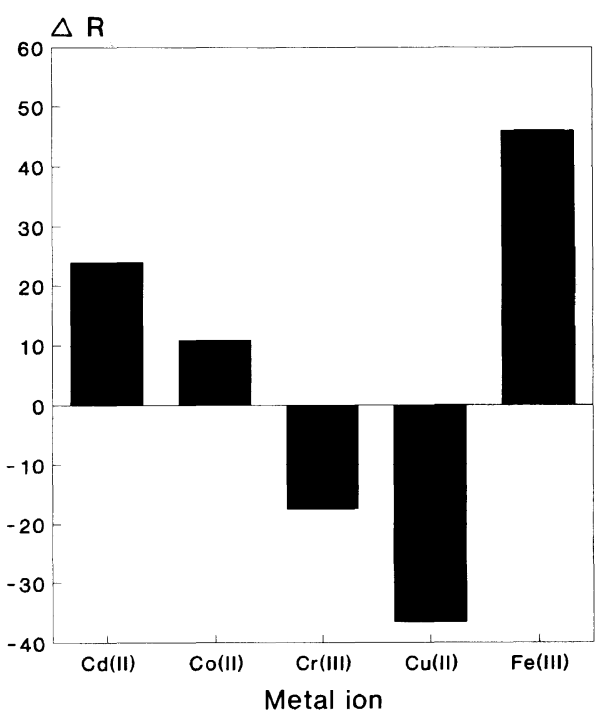

Figure 4. Dependence of the relative retention $\Delta R$ ( $=R_{3 \mathrm{~d}}-R_{3 \mathrm{~b}}$ ) from the type of metal ion for poly $(4-$ vinylpyridine-co- $N$-allylthiourea) (3) at $\mathrm{pH} 3(Z=10)$.

structure. The difference in the interaction behavior becomes transparent in the plot of the separation factor $\beta$ as a function of $Z$ for the system $\mathrm{Cu}^{2+} / \mathrm{Ni}^{2+}$ (Figure 5).

The dramatic increase of $\beta$ for copolymer $\mathbf{3 b}$ with higher filtration factors indicates the importance of the influence of the comonomer composition. For copolymer $\mathbf{3 d}$ only a very slight increase was observed. This selectivity enhancement and also the individual contribution of the constitutional units to the interaction behavior are currently investigated further.

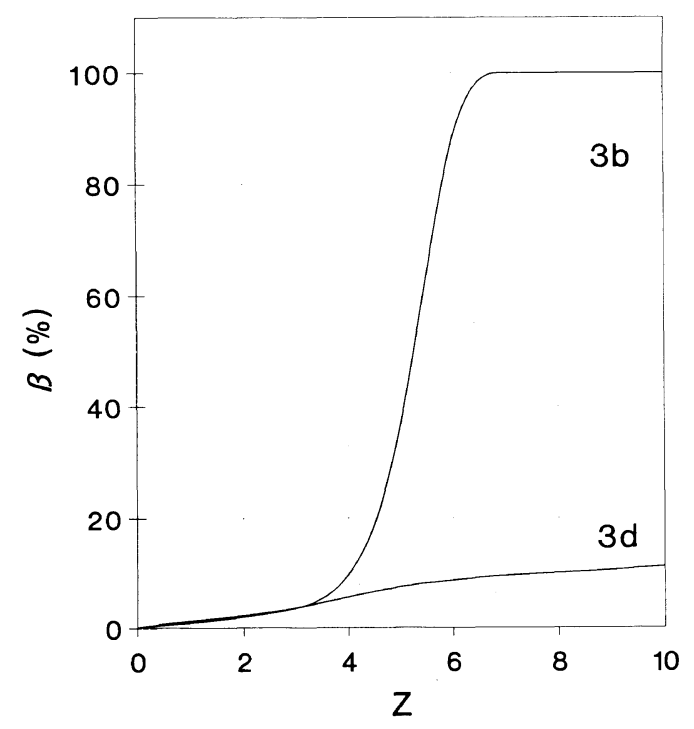

Figure 5. Variation of the separation factor $\beta$ (= $\left.R_{\mathrm{Cu}} R_{\mathrm{Ni}}^{-1}\right)$ with the filtration factor $Z\left(=V_{\mathrm{p}} V_{0}^{-1}\right)$ for the copolymers $\mathbf{3 b}$ and $\mathbf{3 d}$.

Copolymers of $N$-allylthiourea find practical use as additives for mining, oil recovery, and many other processes. Applications of these copolymers include also their use as macromolecular complexing agents for the extraction or removal of hazardous metals from waste water or other industrial fluids. Further studies on the copolymerization with other comonomers and on the interaction behavior of such copolymers with metal ions will be reported in due course.

Acknowledgement. The skilled assistance of 


\section{K. E. GeCKeleR}

Ms. A. Fink with experimental work is gratefully acknowledged.

\section{REFERENCES}

1. C. A. Finch, Ed., "Chemistry and Technology of Water-Soluble Polymers," Plenum Press, New York and London, 1983.

2. K. E. Geckeler, V. N. Pillai, and M. Mutter, $A d v$. Polym. Sci., 39, 65 (1981).

3. H. F. Mark, N. M. Bikales, C. G. Overberger, G. Menges, and J. I. Kroschwitz, Ed,. "Encyclopedia of Polymer Science and Engineering," Vol. 17, John Wiley \& Sons, New York, N.Y., 1985, p 567.

4. H. Nishikawa and E. Tsuchida, J. Phys. Chem., 79, 2072 (1975).
5. E. Tsuchida and H. Hishide, Adv. Polym. Sci., 24, 1 (1977).

6. E. Tsuchida, H. Nishide, and T. Nishiyama, J. Polym. Sci., Polym. Symp., 47, 35 (1974).

7. H. Nishide and E. Tsuchida, Makromol. Chem., 177, 2295 (1976).

8. P. S. Pallavicini, A. Perotti, A. Poggi, B. Seghi, and L. Fabrizzi, J. Am. Chem. Soc., 109, 5139 (1987).

9. P. Ferruti and R. Barbucci, Adv. Polym. Sci., 58, 57 (1984).

10. E. Bayer, K. Weingärtner, and K. Geckeler, Makromol. Chem., Rapid. Commun., 1, 745 (1980).

11. K. E. Geckeler, V. M. Shkinev, and V. Ya. Spivakov, Angew. Makromol. Chem., 155, 151 (1987).

12. K. E. Geckeler. E. Bayer, B. Ya. Spivakov, V. M. Shkinev, and G. A. Vorobeva, Anal. Chim. Acta, 189, 285 (1986). 